\title{
Dynamic Voltage Stability Studies using a Modified IEEE 30-Bus System
}

\author{
Oluwafemi E. Oni, Kamati I. Mbangula, and Innocent E. Davidson
}

\begin{abstract}
Power System stability is an essential study in the planning and operation of an efficient, economic, reliable and secure electric power system because it encompasses all the facet of power systems operations, from planning, to conceptual design stages of the project as well as during the systems operating life span. This paper presents different scenario of power system stability studies on a modified IEEE 30-bus system which is subjected to different faults conditions. A scenario whereby the longest high voltage alternating current (HVAC) line is replaced with a high voltage direct current (HVDC) line was implemented. The results obtained show that the HVDC line enhances system stability more compared to the contemporary HVAC line. Dynamic analysis using RMS simulation tool was used on DigSILENT PowerFactory.
\end{abstract}

Index Terms-CCT, Commutation failure, Dynamic Voltage stability, HVDC, Steady state analysis.

\section{INTRODUCTION}

$\mathrm{R}$ ESTRICTION in transmission network expansion due to reduced right of way (ROW) brings about long distance bulk power transfer. A minor fault on a heavily loaded line may result in cascading problem which can eventually lead to systems collapse if proper preventive measures are not taken. Increase in heavy system load in major urban centre is another major concern. This now goes to the fact that proper systems planning and predictions goes a long way for stable and quality power transfer to major areas that are prone to load increase. $\mathrm{AC}$ lines have been the most commonly means of power transmission from one area to another especially in African countries. But with the inherent problems associated with AC lines such as stability problem, cascading effect, corona loss, synchronism problem, and the situation whereby the generating stations are located far away from load centres. AC lines are not suitable for such transmission being that it requires different compensating devices for a specific distance interval. Solving these problems brings about usage of HVDC lines to transfer bulk power over long distance which also tends to improve the stability margin of the systems.

This paper was submitted for review on August 1, 2016. This work was supported by Eskom Power Plant Engineering Institute, Eskom Centre of Excellence in University of KwaZulu-Natal. Westville campus, South Africa.

O. E Oni is with Electrical Engineering Department, University of KwaZulu-Natal. Durban 4041, South Africa (e-mail: maxiphem@yahoo.com).

K. N. I. Mbangula was with Department Electrical Engineering, University of KwaZulu-Natal. Durban 4041, South Africa. He is now with the Department
Power systems fault such as loss of synchronization of a large power plant, tripping of a load and/or sudden disturbance on a transmission line, most times result in interconnecting systems to enter voltage instability state by not meeting active/reactive power demanded and acceptable voltage at each systems bus. This state can further lead to voltage collapse when all the voltage profile after disturbance is below acceptable limits in an important part of the power systems such that the different part of the systems controllers are stressed beyond their operational limit. Thus, ability of the systems to remain practically intact and regain a state of operating equilibrium makes the system voltage stable.

Much research has been done on voltage stability analysis [1] , [2]. Improvement through the use of FACT devices was discussed in [3]-[5]. The effect of the automatic voltage regulator (AVR), on-load tap changers and power systems stabilizer (PSS) on voltage stability was discussed in [6] and [7], while [8] and [12] extensively discusses the impact of HVDC links on power system stability analysis and improvement.

HVDC transmission became favorable when HVDC converter problems were reduced by the introduction of thyristor based switches. Still a lot of improvement has been made in this area of interest, from HVDC cables, converter transformer, converter technology and topology, etc. and there is still a lot of ongoing research being conducted in this area.

This paper presents an investigation into the impact of HVDC links on power systems operation by considering the line loadings and voltage profile. Also, a dynamic approach with the use of real time simulation RMS tools was also considered in analyzing the critical clearing time with and without HVDC line. The obtained results were compared to determine the extent to which the HVDC system helps in improving voltage stability of the network

\section{Voltage StabiLity ANALYsis}

Voltage stability is the ability of a power system to be able to maintain an acceptable voltage profile at all buses in the power network when operated under healthy conditions or when

of Electrical Engineering, University of Namibia. Ongwediva 3624, Namibia (e-mail: imbangula@unam.na).

I. E. Davidson was with Department of Electrical Engineering, University of KwaZulu-Natal. Durban 4041, South Africa. He is now with the Department of Electrical Power Engineering, Durban University of Technology. Durban 4001, South Africa (e-mail: InnocentD@dut.ac.za). 
subjected to systems disturbance. Fig. 1 shows effect of load increase on voltage profile. More increase in load demand beyond the critical point can result in system collapse [1], [10], [13].

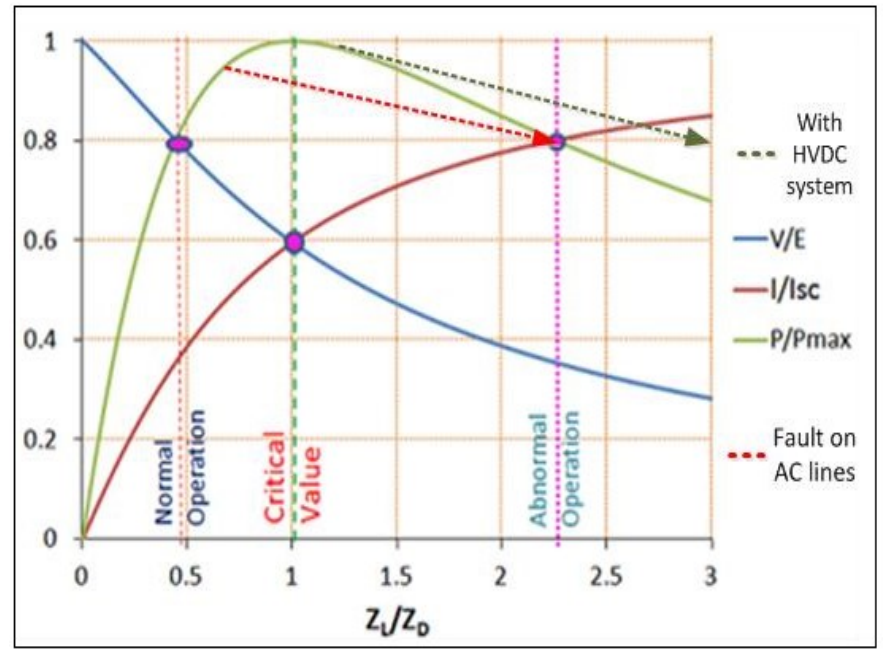

Fig. 1. Receiving end voltage, current and power as a function of load with HVDC line.

\section{A. Static Analysis}

Static analysis of voltage stability involves the use of PV curves to investigate the maximum power that can be transmitted through a transmission line to a load considering the voltage profile of the load bus and the, reactive power needed for the load at specific load power. It can also made use of reduced Jacobian matrix in (1)-(4) to analyse the voltage sensitivity of a particular bus to change in reactive power in that bus while the active power is kept constant [1], [10].

$\left[\begin{array}{l}\Delta P \\ \Delta Q\end{array}\right]=\left[\begin{array}{ll}J_{P \theta} & J_{P V} \\ J_{Q \theta} & J_{Q V}\end{array}\right]\left[\begin{array}{c}\Delta \theta \\ \Delta V\end{array}\right]$

Let $\Delta \mathrm{P}=0$, then,

$\Delta Q=\left\lfloor J_{Q V}-J_{Q \theta} J_{P \theta}^{-1} J_{P V} \llbracket \Delta V\right]$

$\Delta Q=J_{R} \Delta V$

$\Delta V=J_{R}^{-1} \Delta Q$

Where; $\Delta \mathrm{P}$ - Incremental change in bus real power

$\Delta \mathrm{Q}$ - Incremental change in bus Reactive Power

$\Delta \theta$ - Incremental change in bus Voltage phase angle

$\Delta \mathrm{V}$ - Incremental change in bus voltage magnitude

$\mathrm{J}_{\mathrm{R}}{ }^{-1}$ is called the $\mathrm{V}-\mathrm{Q}$ sensitivity as it value determines how stable the system is. A positive value indicates a stable system, while a negative value indicates an unstable system. For a positive value, the smaller the sensitivity value, the more stable the system becomes, meaning as load increases, the value tends towards infinity signifying an unstable system condition.

For the modal analysis that explains different snapshot of voltage sensitivity to reactive power, this is given by (5)-(9).

$J_{R}=\xi \Lambda$

$J_{R}^{-1}=\xi \Lambda^{-1} \eta$

$\Delta V=\xi \Lambda^{-1} \eta \cdot \Delta Q$
Therefore,

$\eta \Delta V=\Lambda^{-1} \eta \cdot \Delta Q$

$v=\Lambda^{-1} q$

$(\mathrm{v}=\eta \cdot \Delta \mathrm{V})$ is the vector for the modal voltage variations and $(\mathrm{q}=\eta \cdot \Delta \mathrm{Q})$ is the modal of reactive power variations.

\section{B. Dynamic Analysis}

Critical Clearing time (CCT) is one of the method used in analyzing the transient rotor angle stability of a power system. This involves the use of real time dynamic analysis to calculate, for a given defined fault, the maximum allowable clearing time in which the system remains transiently stable. This time frame gives the allowance to which the fault must be cleared or isolated from the rest of the system for the power system to remain in a stable state of operation. If the fault clearing time is longer than the $\mathrm{CCT}$, the power system will definitely become unstable [14], [15].

Dynamic voltage stability model comprises of first order differential equations as shown in (10)-(12). ' $x$ ' connotes the state vector of the system and ' $y$ ' represent the network variable like bus voltage. Eq. 10 becomes linear during the case of small disturbance around a steady state equilibrium point $\left(\mathrm{x}_{\mathrm{o}}, \mathrm{y}_{\mathrm{o}}\right)$ and further eliminated to give (12). Static bifurcation, capable of causing voltage collapse will occur when D is zero. Thus an assumption of $\mathrm{D} \neq 0$ is always made for dynamic bifurcation studies.

$$
\begin{aligned}
& x=f(x, y) \\
& 0=g(x, y) \\
& \frac{d \Delta x}{d t}=\left(A-B D^{-1} C\right)=A^{\prime} \Delta x
\end{aligned}
$$

Dynamic voltage stability can then be performed by analyzing the eigenvalues of $A^{\prime}$. (A, B, C and $\mathrm{D}$ are appropriate dimensioned matrices) [1], [16], [17].

\section{METHODOLOGY}

A modified IEEE 30 bus test network was used for this study. Modified in the sense that the IEEE 30 Bus test network is a representation of a portion of the American Electric power system (in the Midwestern US) as of December, 1961. Fig. 2 shows the modified IEEE 30 bus test network as setup on DigSILENT PowerFactory. The modified network consist of 30 buses, 8 generators, 20 loads, 40 lines, 11 transformers, 1 shunt capacitor, and 1 shunt reactor. The main voltage level of the network is $400 \mathrm{kV}$ (nominal voltage) with nominal transmitting frequency of $50 \mathrm{~Hz}$. The $132 \mathrm{kV}$ of bus 19 , bus 20 and bus 21 , and the $11 \mathrm{kV}$ of bus 15 and bus 18 was assumed on power factory for this study.

\section{A. Model Parameters}

The model parameters were based on calculations and use of standard IEEE models, due to the fact that most data unit were not specified by different online sources for the IEEE 30 bus systems.

Since $\xi^{-1}=\eta$, i.e. an identity matrix. 


\section{1) Load model}

The loads are modelled to be voltage dependent with constant active and reactive power demand for load flow calculation and for stability analysis according to (13). The value of $\mathrm{kp}$ is set to be 1 for active power (constant current behaviour) and 2 for the reactive power (constant impedance) [18].

$$
P+j Q=P_{\mathrm{o}}\left(\frac{U}{U_{\mathrm{o}}}\right)^{k p}+Q_{\mathrm{o}}\left(\frac{U}{U_{\mathrm{o}}}\right)^{k p}
$$

2) Generator model

All the generators are connected via a transformer. SM (synchronous machine) was used on PowerFactory to name all the generators. Table I shows the generator parameter as used on DigSILENT. SM 1.1 with $0^{0}$ voltage angle and $1.00 \mathrm{pu}$ voltage set-point was used as the reference machine because it is connected to the bus with the highest fault level. All generator were set to be in voltage control mode.

Two generator type were used as shown in Table II, first is the $16.5 \mathrm{KV}, 500 \mathrm{MVA}$ used by SM 3, 5 and 6 and the other synchronous machine uses the $20 \mathrm{KV}, 800 \mathrm{MVA}$ type. Transformer parameter used is shown in Table III.

TABLE I

GENERATOR PARAMETER

\begin{tabular}{ccc|ccc}
\multicolumn{7}{c}{ GENERATOR PARAMETER } \\
\hline \hline SM & MW & Mvar & SM & MW & Mvar \\
\hline $\mathbf{1 . 1}$ & Slack & 5 & 4.1 & 720 & 5 \\
$\mathbf{1 . 2}$ & 700 & 0 & 4.2 & 720 & 0 \\
$\mathbf{2}$ & 320 & 0 & $\mathbf{5}$ & 390 & 0 \\
$\mathbf{3}$ & 407 & 0 & $\mathbf{6}$ & 385 & 5 \\
\hline \hline
\end{tabular}

TABLE II

SYNCHRONOUS MACHINE TYPE DATA

\begin{tabular}{cccccccc}
\hline \hline SM & MVA & $\mathrm{kv}$ & $\begin{array}{c}\mathrm{xd} \\
(\mathrm{pu})\end{array}$ & $\begin{array}{c}\mathrm{xl} \\
(\mathrm{pu})\end{array}$ & $\begin{array}{c}\mathrm{xq} \\
(\mathrm{pu})\end{array}$ & $\begin{array}{c}\mathrm{Td}^{\prime} \\
(\mathrm{s})\end{array}$ & $\begin{array}{c}\mathrm{Tq}^{\prime} \\
(\mathrm{s})\end{array}$ \\
\hline $\boldsymbol{T}$ Typ1 & 800 & 20 & 2.2 & 0.3 & 2.2 & 2.1 & 0.28 \\
Typ2 & 500 & 16.5 & 1.3 & 0.15 & 2.0 & 1.0 & 1.0 \\
\hline \hline
\end{tabular}

TABLE III

TRANSFORMER TYPE DATA

\begin{tabular}{cccccc}
\hline \hline & $\begin{array}{c}\text { Sn } \\
\text { MVA }\end{array}$ & KV & $\begin{array}{c}\text { uk \& } \\
\text { uk0 }\end{array}$ & $\begin{array}{c}\text { Vector. } \\
\text { group }\end{array}$ & ULTC \\
\hline $\boldsymbol{T r f 1}$ & 400 & $11 / 400$ & 12.6 & YNd1 & -5 to 5 \\
$\boldsymbol{T r f 2}$ & 600 & $16.5 / 400$ & 14.88 & YNd1 & -4 to 4 \\
$\boldsymbol{T r f 3}$ & 850 & $20 / 400$ & 14.44 & YNd1 & -5 to 5 \\
$\boldsymbol{T r f 4}$ & 400 & $132 / 400$ & 11.82 & YNyn & -3 to 3 \\
\hline \hline
\end{tabular}

All generators are rated for realistic inertial time constant and modelled using the IEEE controller model on PowerFactory for the automatic voltage regulator, governor control as well as the power systems stabilizer (but the PSS for all the generator are disable due to set point error).

\section{3) HVDC model}

The HVDC network is modelled as depicted in Fig. 3 with the parameter on Table $1 \mathrm{~V}$. The 1350MW monopolar with $600 \mathrm{KV}$ operating voltage transmits power over a distance of $700 \mathrm{~km}$. The reliability of the HVDC network was put to test using a three phase fault at the inverter terminal (fault reactance of $10 \Omega$ for $200 \mathrm{~ms}$. Result shows a commutation failure at the inverter side of the converter which the voltage dependent current order limiter (VDCOL) was activated as a result of reduction in DC voltage. The commutation failure was resolved when the rectifier controller reduces the DC current to allow minimum power across the link during fault conditions. With this, most of the DC faults are self-clearing with the help of a well-equipped controller.

Equations (14) and (15) show the fundamental law governing the HVDC systems. HVDC equivalent circuits' equation is given by (16).

$V_{d I}=\frac{3 \sqrt{2} \alpha_{I} V_{t I} \cos \gamma_{I}-3 X_{C} I_{D}}{\pi}$

$V_{d R}=\frac{3 \sqrt{2} \alpha_{R} V_{t R} \cos \alpha_{R}-3 X_{C} I_{d}}{\pi}$

$I_{d}=\frac{V_{d o r} \cos \alpha-V_{d o i} \cos \beta \cos \gamma}{R_{c r}+R_{L} \pm R_{c i}}$

HVDC control as set up on DigSILENT PowerFactory software can be divided into two hierarchical levels: inverter control and rectifier control. A block definition that defines the transfer function in the form of graphical block diagrams and equation is first created for each of the controllers, and then a composite block frame is created for the overall control. This consists of the entire overview diagram showing all the slots interconnections and which object should be assign to a slot. After a common model is created from the block definition, they are then added into the composite model. Fig. 4 and 5 from [19] give a simple overview diagram of the controller as connected to the converter.

\begin{tabular}{ccc} 
& TABLE IV & \\
& HVDC DATA & \\
\hline \hline AC Voltage $(\mathrm{KV})$ & Rectifier & Inverter \\
\hline Firing angle control & 400 & 400 \\
Commutation Reactance & $13.445 \Omega$ & Voltage control \\
Tap changer control & $\alpha$-control & $13.445 \Omega$ \\
Actual winding ratio & 0.97 & $\gamma$-control \\
\hline \hline
\end{tabular}






Fig. 2. Single line diagram of the modified IEEE 30 bus system.

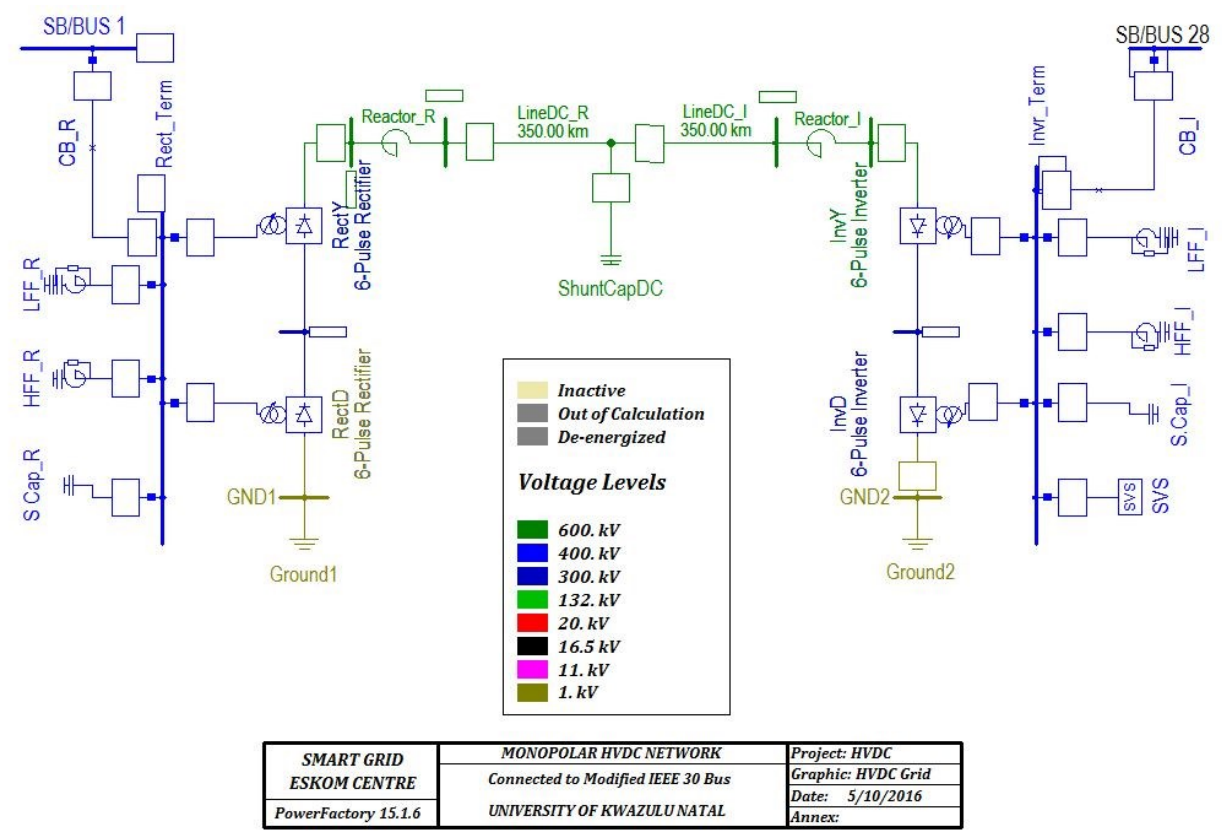

Fig. 3. Monopolar HVDC model. 


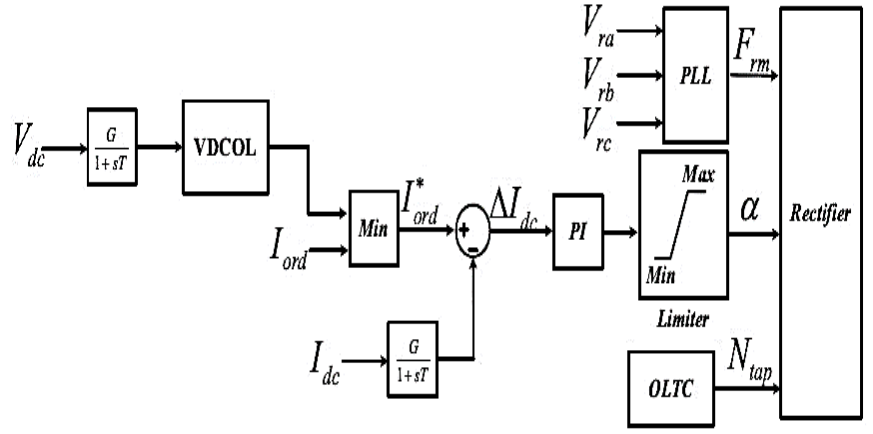

Fig. 4. Rectifier Controller.

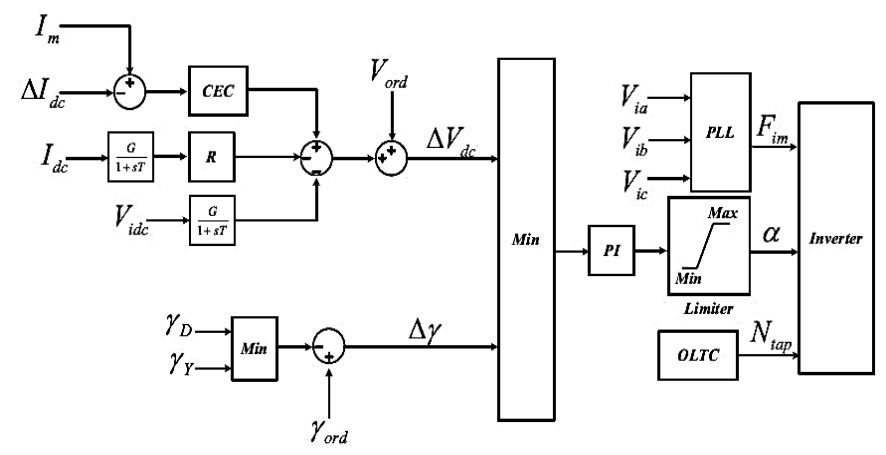

Fig. 5. Inverter Controller.

\section{Simulation Result}

The results consist of both the steady state power flow results which are depicted in bar graphs and transient stability analysis results which are configured using the real time RMS simulation.

\section{A. Steady-State Load Flow}

The steady state load flow results follows the Newton Raphson iterative equation for power flow calculation. Fig. 4 to 8 show the steady load flow presented in a bar diagram format for the bus voltage magnitudes, the line loading, and load active and reactive power respectively. From the line loading diagram, the transmission line connecting bus 3 and 1 , and the line connecting bus 8 and 3 is already overloaded beyond their ratings, even transmission line connecting bus 9 to bus 13 . However, the HVDC line is out of service, so as to know the systems condition when only AC lines is in operation (meaning HVDC system is out of service). Fig. 8 present active load demand in the IEEE 30-bus system.

\section{B. Time-Domain Stability Simulation}

Two operational scenarios were considered in this study. The first scenario is when the power is being transmitted using AC lines only, and the second scenario is when an existing longest $\mathrm{AC}$ line is replaced with an HVDC line and the results are depicted on a graph. Bus voltage and generator excitation current are the main object of focus for this study.

For the bus voltage magnitude graph, specific busbar that are prone to voltage instability was selected rather than use all the 30 buses of the network.

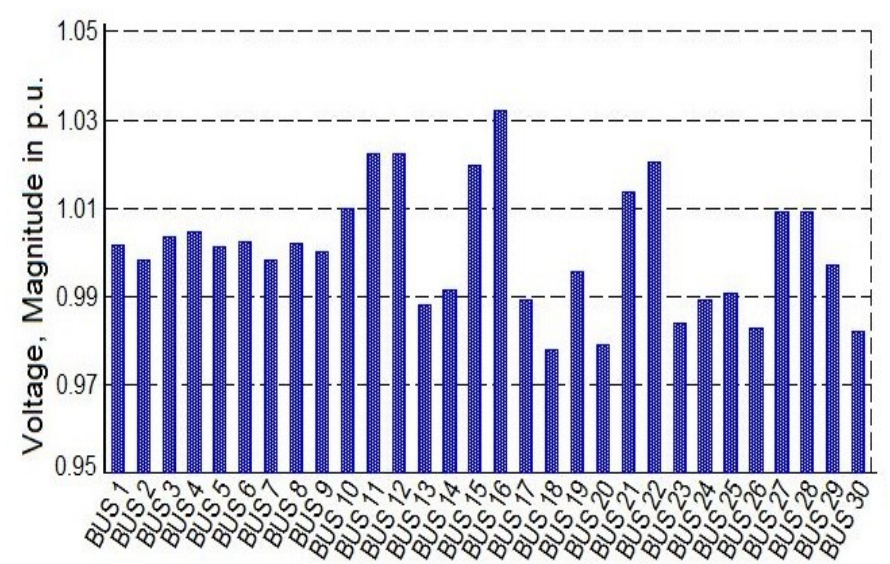

Fig. 6. Busbar voltage magnitudes.

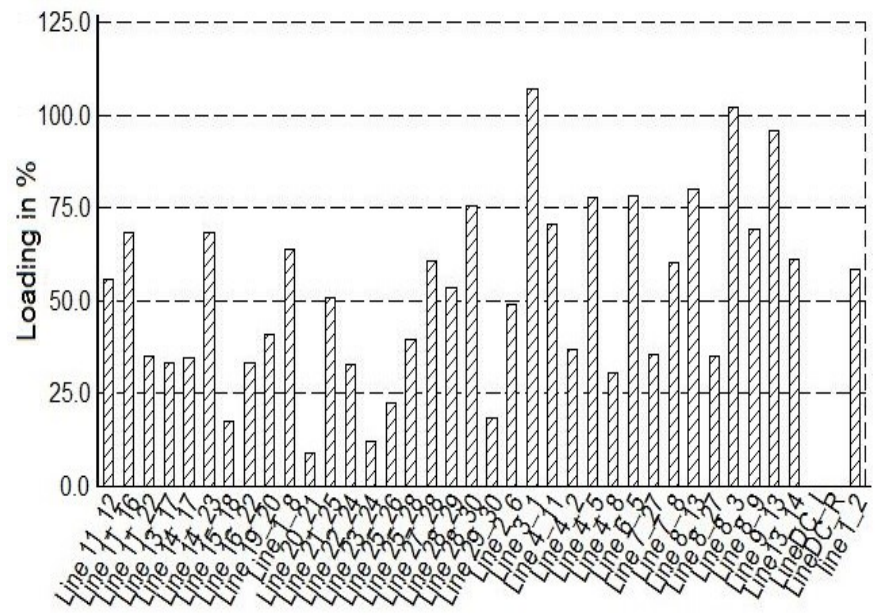

Fig. 7. Line loading (AC Lines only).

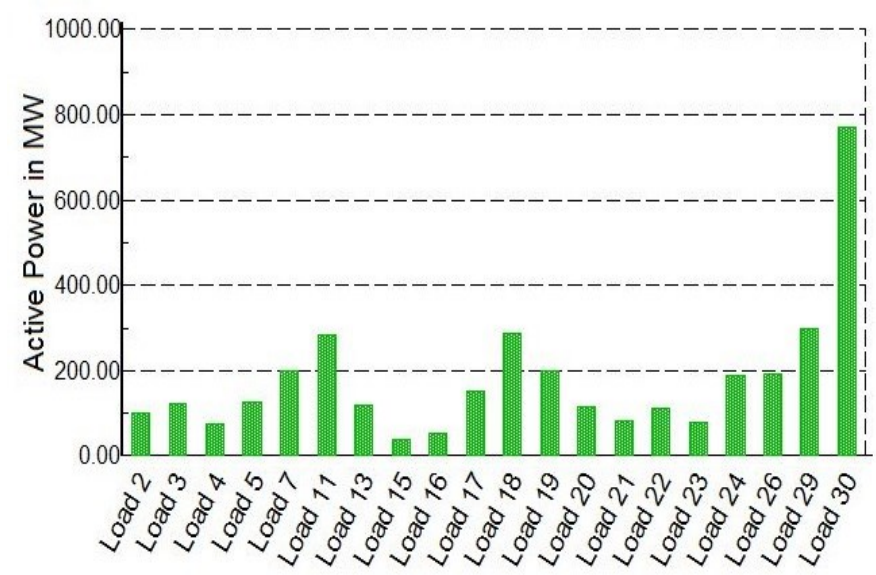

Fig. 8. Load active power.

\section{1) First scenario (without HVDC)}

Different study cases was carried out while using the time domain simulation to investigate the weakest area of the network. This involve the use of critical clearing time to observe the maximum time a fault can stay on each of the element on the network (busbar and lines). Three phase short circuit fault was placed on each of the busbar once at a time and their CCT was estimated. It was observed that bus 8 has the least critical time. The same process was also carried out on the line (placing the fault at the beginning of the line) and cleared 
by switching off the line.

Fig. 9-11 show the bus voltage magnitude, generator rotor angle and its excitation current when a three phase fault placed at the beginning of 'line 1_3' was simulated and the fault cleared by switching the line off after $100 \mathrm{~ms}$. This is the maximum allowable time the fault can stay on the line for the system to be stable when using only AC lines to transmit power from one region to another. During the fault, the bus voltage dips down to about $0.11 \mathrm{pu}$, but the generator exciter helps to restore the system back to stability by increasing the field current winding of the synchronous generator. Thereby automatically adjust the field current to maintain the required terminal voltage.

Fig. 12-14 shows a situation whereby the fault stay more than expected time before the circuit breaker of the line was opened (120ms). This caused the generator to have yielded all its excitation limit and the systems enter instability when the voltage profile of all the buses cannot be met again. This causes the generator angle to swing $360^{\circ}$ off from the reference machine, a situation caused when the generator pole slipped.

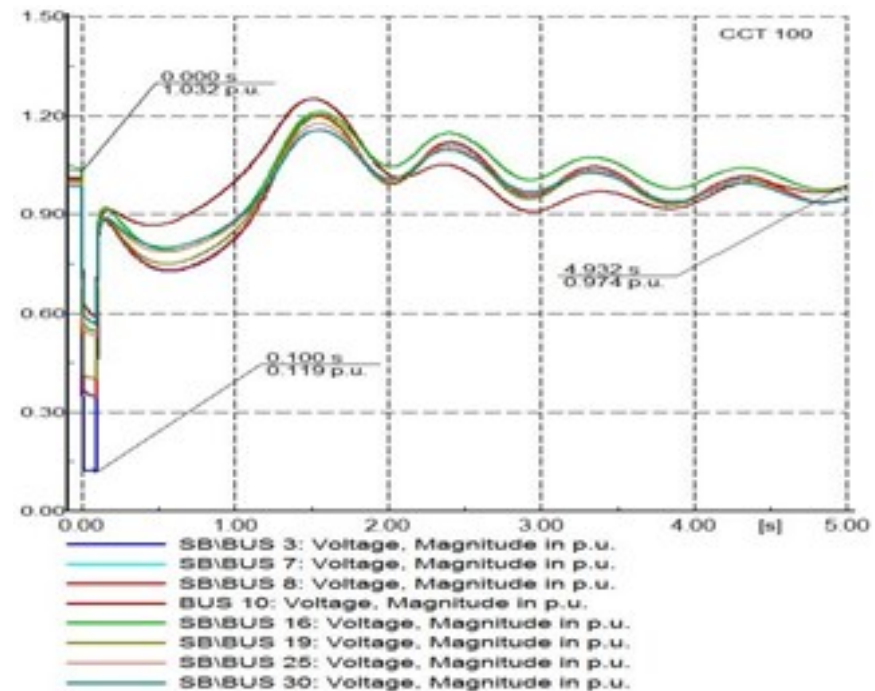

Fig. 9. Voltage Plot during fault on 'Line 31 ', cleared by switching off the line after 100ms. (Without HVDC line).

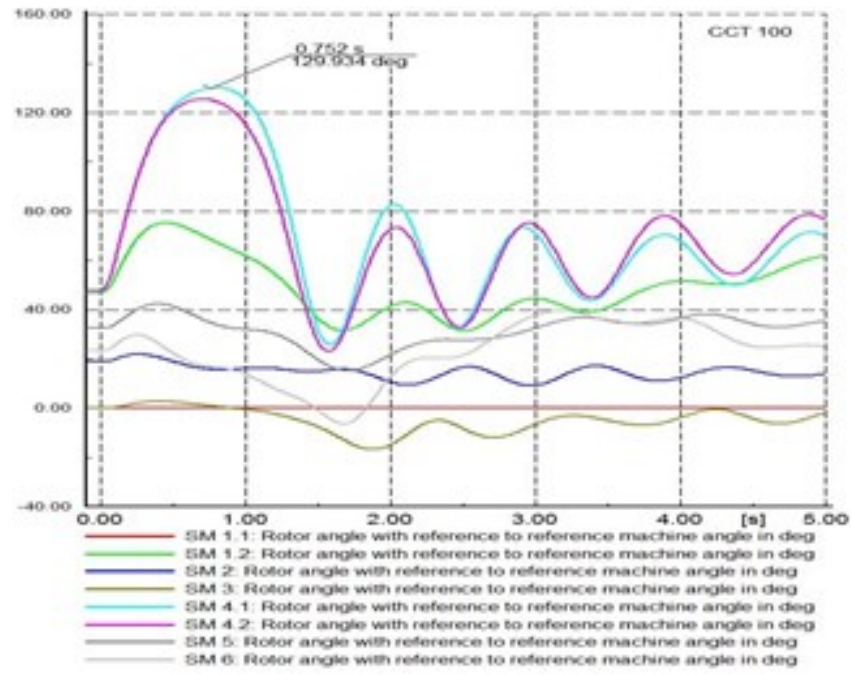

Fig. 10. Generators rotor angle (Without HVDC line).

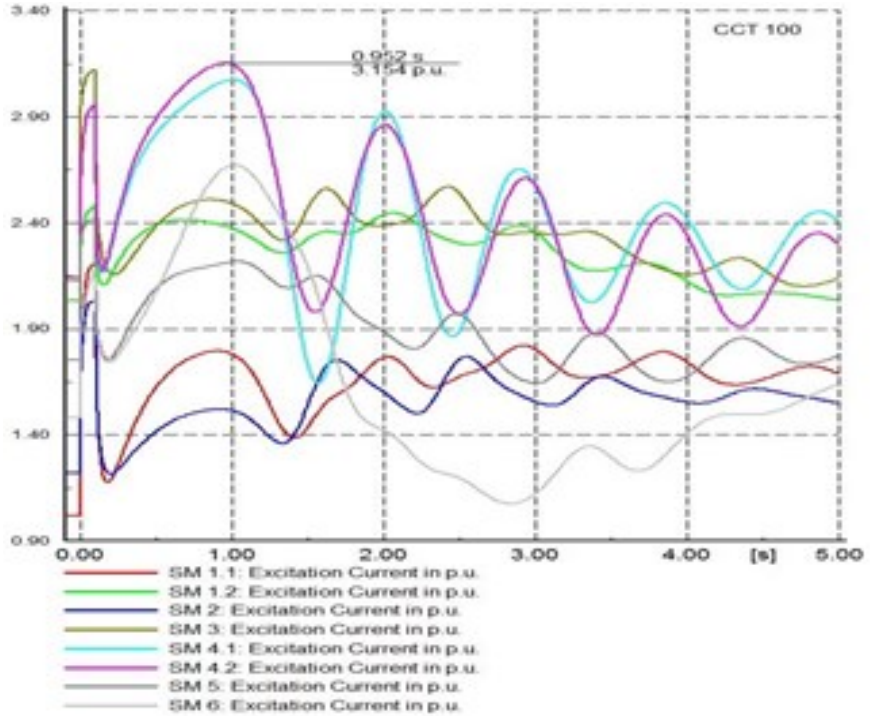

Fig. 11. Generator excitation current (Without HVDC line).

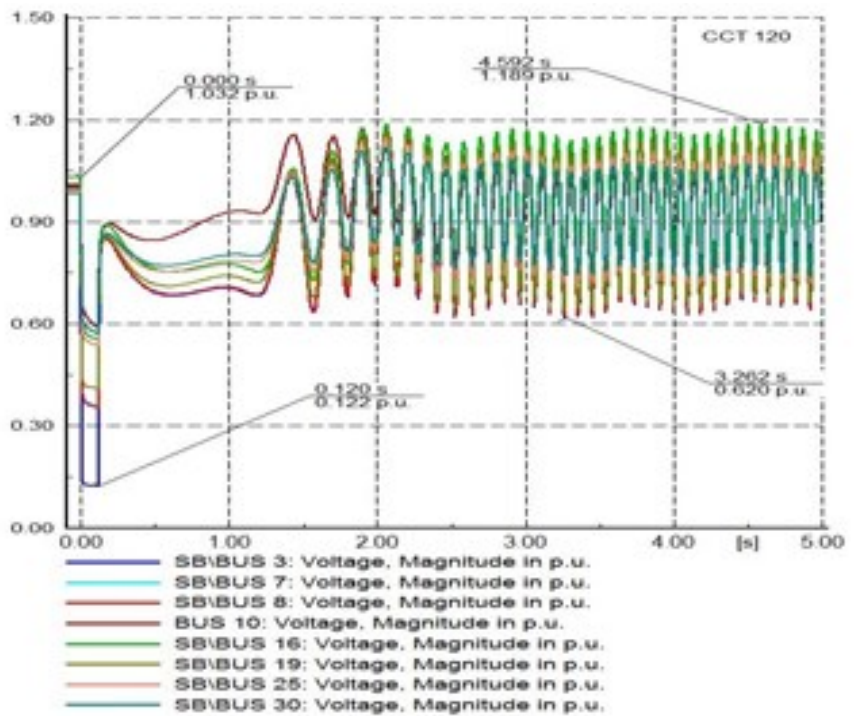

Fig. 12. Voltage Plot during fault on 'Line 1_3', cleared by switching off the line after $120 \mathrm{~ms}$. (Without HVDC line)

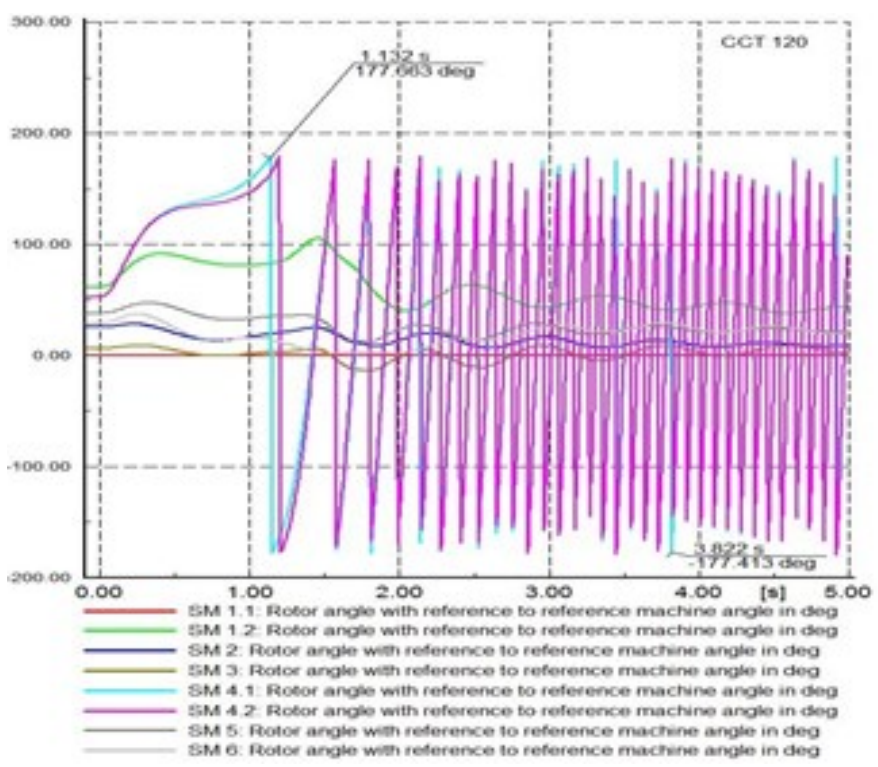

Fig. 13. Generator Rotor angle fault (Without HVDC line) 


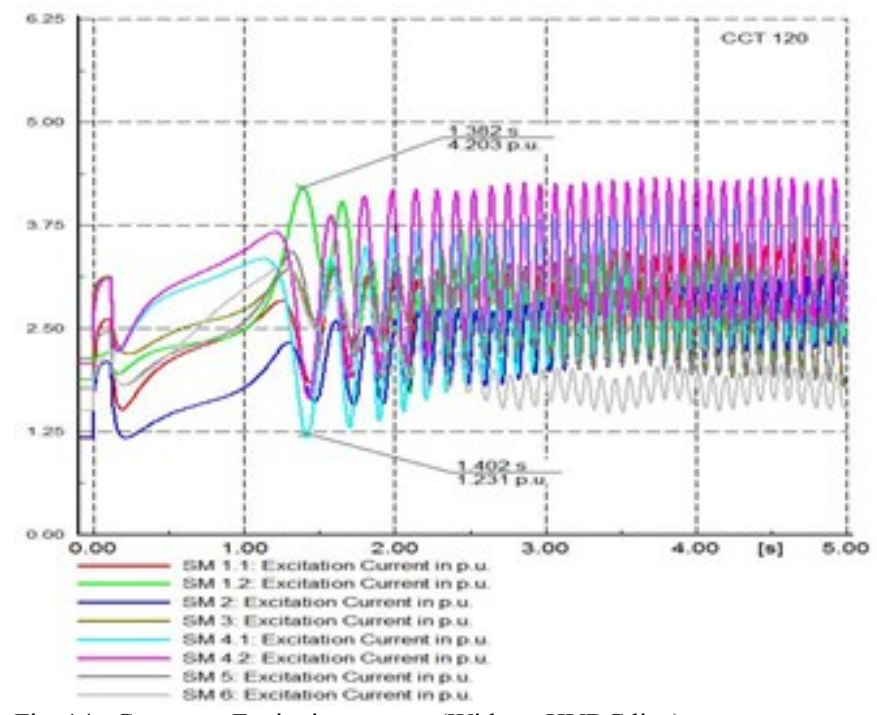

Fig. 14. Generator Excitation current (Without HVDC line)

2) Second scenario (With HVDC line).

When existing AC 'line 8_27' was replaced with a monopolar HVDC system as shown in fig. 3, the load flow result for the lines loading are shown below in Fig. 15, with all lines loading within acceptable range.

The same three phase fault scenario was carried out on 'Line $3 \_1$ ' and the fault cleared by isolating the line after $120 \mathrm{~ms}$ while using HVDC line to interconnect 'bus 1' to 'bus 28', it was found out that the system was stable even until it reaches a maximum time of $150 \mathrm{~ms}$. Further increase of fault clearing duration beyond this limit resorted in convergence error. Fig. 16-18 shows the bus voltage magnitude, generator rotor angle and excitation current respectively.

A case of commutation failure occur at the inverter side of the HVDC link during fault period, but with the help of the converter selection mode by blocking the fault current from transferring into the HVDC link, the systems was able to maintain stability. HVDC systems thus help to increase the time duration a fault can stay on the line before being isolated from the systems. All different study cases carried out on the systems prove the efficacy of HVDC link in power systems stability and control during system disturbance.

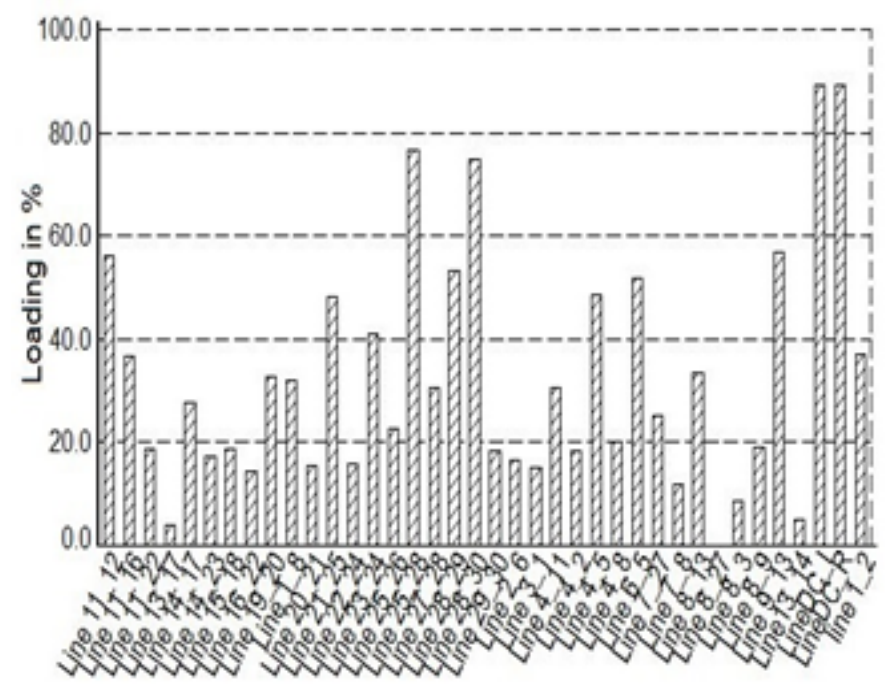

Fig. 15. Line loading (with HVDC line).

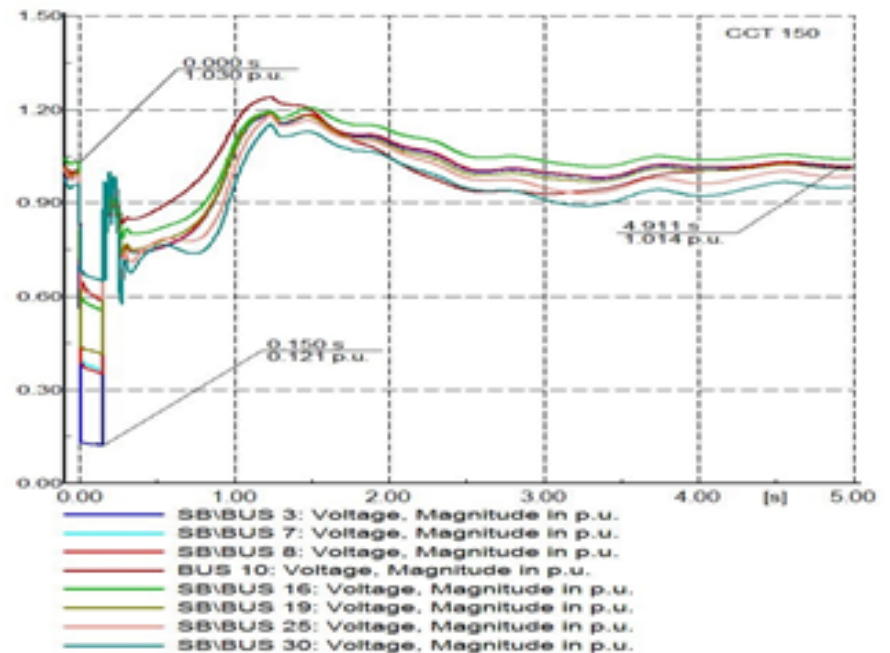

Fig. 16. Voltage Plot during fault on 'Line 31 1', cleared by switching off the line after $150 \mathrm{~ms}$. (With HVDC line).



Fig. 17. Generators rotor angle (With HVDC line).

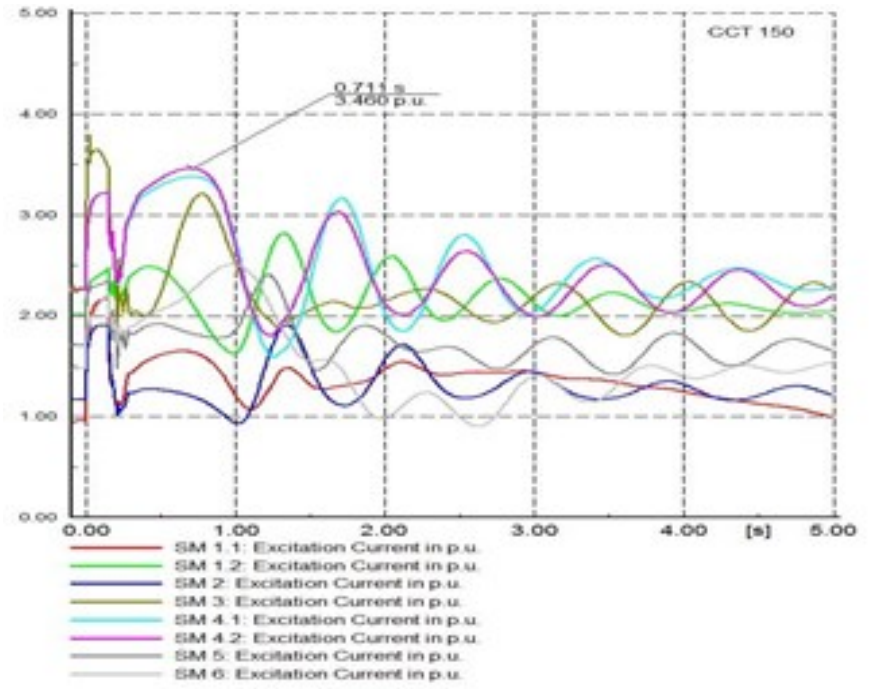

Fig. 18. Excitation current. (With HVDC line). 


\section{CONCLUSION}

Impact of HVDC scheme on AC systems short term voltage stability study was investigated in this study, and based on this study; it was found out that HVDC systems helps in enhancing voltage stability than the AC line, in that it helps to improve the critical clearing/isolating time for disturbances on the systems. The effect of VDCOL in HVDC link during systems disturbance was also analyzed. The strategies for improving voltage stability are thus proposed; that HVDC lines improve dynamic voltage stability of power systems.

Although, different FACTs devises and a well modelled generator controller helps in enhancing voltage stability of a system. However, this cannot be compared to the benefit which HVDC systems offers, namely; little line losses, long distance bulk power transfer, immunity to cascading effect, bi-direction power transfer, small right of way, asynchronous interconnection etc. Initial cost of constructing converter station can be a little expensive, but the cost saved by transmission line construction with associated losses in DC systems outweigh the latter. And with the emergence of new power electronic converter and well rugged controller, HVDC system will be the best mode to transmit bulk power due to high efficiency and economics of transmission that it offers.

\section{REFERENCES}

[1] G. Morison, B. Gao, and P. Kundur, "Voltage stability analysis using static and dynamic approaches," IEEE Transactions on Power Systems, , vol. 8, pp. 1159-1171, 1993.

[2] T. Van Cutsem and C. Vournas, Voltage stability of electric power systems vol. 441: Springer Science \& Business Media, 1998.

[3] M. Noroozian, L. Ängquist, M. Ghandhari, and G. Andersson, "Improving Power System Dynamics by Series-Connected FACTS Devices," IEEE Transactions on Power Delivery, , vol. 12, pp. 1635-1641, 1997.

[4] Y.-H. Song and A. Johns, Flexible AC Transmission Systems (FACTS): IET, 1999.

[5] S. Gasperic and R. Mihalic, "The Impact of Serial Controllable FACTS Devices on Voltage Stability," International Journal of Electrical Power \& Energy Systems, vol. 64, pp. 1040-1048, 2015.

[6] C. Vournas and M. Karystianos, "Load Tap Changers in Emergency and Preventive Voltage Stability Control," Transactions on Power Systems, IEEE, vol. 19, pp. 492-498, 2004.

[7] Y. Wang, D. J. Hill, R. H. Middleton, and L. Gao, "Transient Stability Enhancement and Voltage Regulation of Power Systems," IEEE Transactions on Power Systems, , vol. 8, pp. 620-627, 1993.

[8] D. L. H. Aik and G. Andersson, "Power Stability Analysis of Multi-Infeed HVDC Systems," IEEE Transactions on Power Delivery, , vol. 13, pp. 923-931, 1998.

[9] Hammad, "Stability and Control of HVDC and AC Transmissions in Parallel," IEEE Transactions on Power Delivery, vol. 14, pp. 1545-1554, 1999.

[10] O. E. Oni, K.N.I. Mbangula and I.E. Davidson, "Voltage Stability Improvement of a Multi-Machine System using HVDC," Proceedings of the Clemson University Power Systems Conference (PSC), March 8-11, 2016, Clemson University, Clemson, SC, USA.

[11] K. N. I. Mbangula, I. E. Davidson and R. Tiako, "Improving Power System Stability of South Africa's HVAC Network Using Strategic Placement of HVDC Links", CIGRE Science \& Engineering Journal (CSE), Vol. 5, June 2016, pp. 71-78.

[12] K.N.I. Mbangula, O.E. Oni and I.E. Davidson, "The Impact of HVDC Schemes on Network Transient Rotor Angle Stability". In Proceedings of the 24th South African Universities Power Engineering Conference, 2628 January 2016, Vereeniging, South Africa, pp. 461 - 466, ISBN 978-177012-386.

[13] DigSILENT PowerFactory: Power System Stability Seminar DigSILENT Buyisa (Pty) Ltd.
[14] W. A. Oyekanmi, G. Radman, A. A. Babalola, and T. O. Ajewole, "Effects of STATCOM on the Critical Clearing Time of Faults in MultiMachine Power Systems During Transient Stability Analysis Studies," in 2014 IEEE 6th International Conference on Adaptive Science \& Technology (ICAST), 2014, pp. 1-6.

[15] R. Kamdar, M. Kumar, and G. Agnihotri, "Transient Stability Analysis and Enhancement of IEEE-9 Bus System. Electrical \& Computer Engineering: An International Journal (ECIJ) Volume 3, Number 2, June 2014"

[16] J. Chow and A. Gebreselassie, "Dynamic Voltage Stability Analysis of a Single Machine Constant Power Load System," in Proceedings of the 29th IEEE Conference on Decision and Control, 1990, pp. 3057-3062.

[17] B. H. Lee and K. Y. Lee, "Dynamic and Static Voltage Stability Enhancement of Power Systems," IEEE Transactions on Power Systems, , vol. 8, pp. 231-238, 1993.

[18] DigSILENT PowerFactory: Technical Reference Documentation General Load, Gomaringen, Germany, 2013.

[19] D. Kong, "Advanced HVDC Systems for Renewable Energy Integration and Power Transmission: Modelling and Control for Power System Transient Stability," Doctor of Philosophy, School of Electronic, Electrical and Computer Engineering, University of Birmingham, Birmingham, 2013.

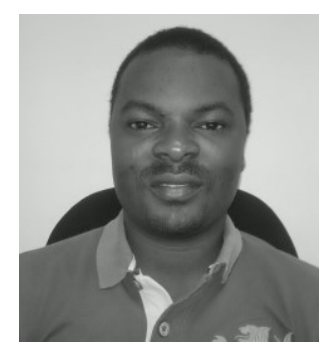

Oluwafemi E. Oni was born in Nigeria on 17 September 1988. He received his BSc (honours) Degree in Electrical and electronic engineering from Ekiti State University, Ado Ekiti, Nigeria, in 2013. He then proceed to University of KwaZuluNatal, Durban, South Africa in 2015 for his MSc degree in electrical engineering (currently handed in his Thesis for examination).

He was a system and maintenance engineer at Egbin Power Thermal Plant, Lagos, Nigeria, in 2012 and Omotosho Power plant, Ore, Nigeria, in 2013/2014. He is currently a Research Assistance with Department of Electrical Engineering, University of KwaZulu-Natal. His research includes power systems stability analysis using High Voltage Direct Current transmission scheme, integration of renewable energy into the grid using multi-terminal HVDC scheme, and smart grid systems using FACTs.

Mr. Oni's award and honors include MTN foundation scholarships, ETISALAT scholarship and Ekiti state scholarship.

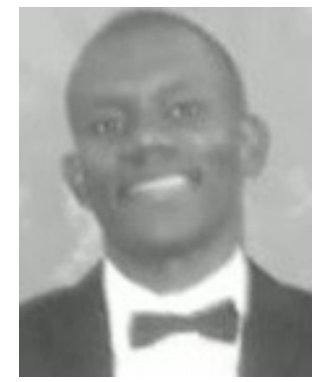

Kamati N.I. Mbangula was born in Namibia on 20 August 1989. He graduated with a BSc. (Honours) Degree in Electrical Engineering from the University of Namibia (UNAM). He pursued his postgraduate studies in South Africa at the University of KwaZulu-Natal (RSA), and carried out his research at the Eskom Centre of Excellence in High Voltage Direct Current (HVDC). His work experience includes working as a Staff Development Fellow at UNAM, and working as a research assistant and lab technician at the Eskom centre of excellence in HVDC. He is currently employed as a lecturer at UNAM. His fields of interests include power systems stability analysis, and low voltage reticulation systems design and analysis. 


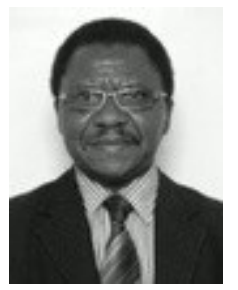

Innocent E. Davidson (M'92-SM'02) received the BSc (Hons) and MSc degrees in Electrical Engineering from University of Ilorin in 1984, and 1987 respectively. $\mathrm{PhD}$ in electrical engineering from the University of Cape Town, Rondebosch, South Africa1998; and Postgraduate Diploma in business management from the University of KwaZulu-Natal, South Africa, 2004; Associate Certificate, sustainable energy management, British Columbia Institute of Technology, Burnaby, Canada, 2011.

From 1994-1995, he was Engineering Inspector, Rainbow Energy Project at EASIGAS (Pty) Ltd, Cape Town; Senior Lecturer, University of Pretoria (1999-2001); Senior Lecturer, Department of Electrical Engineering, University of KwaZuluNatal (UKZN), 2001-2006; Part-time Instructor, Graduate Engineering Program (Power \& Energy), UKZN High Voltage DC Centre (2000-2008) a program co-offered by UKZN and Eskom - South Africa's Electric Utility. From 2005-2006, he was a Visiting Professor, Powertech Labs Inc., Surrey, BC, a world leading consortium in clean energy technologies, independent testing services, power system solutions and smart utility services. From 2007-2011 he was Energy Consultant in Surrey, BC, implementing energy efficiency (electricity/gas) measures, British Columbia provincial government's mandate on Climate Change. He has been an invited guest writer for the IEEE Power and Energy technical magazine as an Expert on Africa: "Energizing Africa's Emerging Economy", IEEE Power and Energy, Vol. 3, No 4, July/August 2005. He was Associate Professor of Electrical Engineering and Research Coordinator, University of Namibia (2012-2014); Director, Eskom Centre of Excellence in HVDC Engineering, UKZN (2014-2016). Currently, he is a Full Professor of Electrical Engineering, Durban University of Technology, South Africa. $\mathrm{He}$ is the author/co-author of over 150-refereed journal and conference papers. His research focus is on Grid integration of renewable energy using Smart Technologies and Innovation for Smart Cities.

Prof Davidson is a member, Western Canada Group of Chartered Engineers (WCGCE); the Institute of Engineering and Technology (IET Canada) British Columbia Chapter; a Chartered Engineer, C.Eng. United Kingdom. He is a Fellow of the South African Institute of Electrical Engineers and a registered professional engineer, P. Eng. (ECSA), South Africa. 